\title{
A Deconstruction of Borderline Personality Disorder
}

\author{
Michael Barclay \\ Feather River College, Meridan University, Petaluma, CA, USA \\ Email: michaelb@sonic.net
}

Received 13 May 2015; accepted 26 July 2015; published 30 July 2015

Copyright (C) 2015 by author and Scientific Research Publishing Inc.

This work is licensed under the Creative Commons Attribution International License (CC BY). http://creativecommons.org/licenses/by/4.0/

c) (i) Open Access

\begin{abstract}
BPD is a disorder of many aspects, levels, meanings, presenting symptoms and issues. It demands deconstruction so that the blueprint of its development can provide a model for its treatment. Deconstruction can only be accomplished theoretically. This paper attempts to provide a theoretical perspective on both the development of the syndrome and a possible view of its treatment. The paper reviews the theories of BLPD and the steady reification of the diagnosis in order to provide a phenomenological alternative and a compassionate method of treatment.
\end{abstract}

Keywords

Psychological Diagnosis, Borderline Personality, Deconstruction, Phenomenological

\section{Introduction}

The purpose of this paper is to raise the possibility that the focus of treatment applied to individuals who are considered as borderline personalities and need immediate reconsideration. What practitioners focus on may be both paradoxically appropriate and yet misguided. This paper begins by deconstructing the diagnosis of borderline personality disorder so that the focus of treatment can be understood in a different way. Diagnostic practice contributes to a reification of the condition. That is, Borderline Personality Disorder (BLPD) is considered as a real thing, not necessarily subject to revision, reconsideration or perhaps even theoretical critique. It can be argued that most practitioners understand the level of metaphor on which a diagnosis functions. Nevertheless, it is always useful to remember the metaphoric reality of diagnostic language. However, many diagnosticians imagine it to be fully accurate and literal, as it were. I have suggested elsewhere that the roots of literal language are in metaphor (e.g. Barclay, 1997a, 1997b).

Since Masterson developed a useful psychoanalytic description of the issues and etiology of the disorder, the BLPD diagnosis may have become more and more reified as time went by. How this happened is not a focus of 
this paper, but insights into that etiology might arise as a result of the following critique.

In brief, the course of the disorder has a developmental quality. Masterson points to childhood issues that begin a process that result in BLPD. He notes (1976) "between the ages of 18 months and 36 months a conflict develops in the child between his own developmental push for individuation and autonomy, and fear of the withdrawal of the mothers' emotional supplies that this growth would entail” (p. 38). Masterson says that a mother's approval is necessary for healthy ego development. He notes that if the necessary approval is not provided, the child experiences the withdrawal of support as "the first seeds of his feelings of abandonment (depression, rage, panic, guilt, passivity and helplessness, emptiness and void) which have such far reaching consequences" (p. 38). Masterson calls these identified elements the "Six Horsemen of the Apocalypse"-a metaphor that is both apt and yet peculiar given that it is a religious metaphor and as a result catastrophic.

While the description and theory are both seminal and quite useful, understanding the developmental quality of the disorder itself may be necessary at this point in time. Beginning with Masterson's apocalyptic conceptualization, we can see that good parenting or lack thereof is essential to the development of issues in the individual child. Masterson's conception begins our assay of borderline syndrome and helps us begin our conceptualizing. Emphasis is situated on the evolution, so to speak, of the disorder itself.

The development of BLPD, in my opinion, follows an identifiable course. In brief, it begins, as Masterson suggests, in childhood or adolescence with trauma—psychological (especially emotional), physical or sexual. Masterson's description of the 18 to 36 month old child turns our attention to the trauma of perceived abandonment. Almost always the trauma appears life threatening, especially if the individual is an infant or a child. This experience of threat produces posttraumatic stress. And, it begins the development of BLPD both in our conception and in Masterson's. Following this stressor, anxiety arises. Anxious responses to the world at large characterize the threatened individual's experience. That is, the individual sees the world through anxious eyes, as it were. Common experiences are perceived as nerve-racking, worrisome, and essentially anxiety producing. Perception and interpretation of events in a social milieu are transformed in virtue of the anxiety arising from posttraumatic stress that leaves its mark both cognitively and unconsciously. The indelible effect of trauma and the anxiety that ensues creates over time a sort of exhaustion. In other words, anxiety that is unremitting, overwhelming and unrelenting has an effect both on the emotional and physical state of the individual infant, child or adolescent. Exhaustion is simply one way of describing that effect, and other descriptive phrases might be equally adequate and perhaps even more expansive. Nevertheless, the exhaustion emanating from anxiety and trauma grows. The overwhelming experience of this exhaustion creates a sense of despondency, despair, desolation, hopelessness, tearfulness and dysthymia. These become habitual defensive behaviors in response to repeated events or threats. Clinically, the individual becomes depressed. But the anxiety is not supplanted by the despair or depression. Both the anxiety and depressive qualities are classic results of traumatic experiences. But it can appear that the depression eventuates from the unrelenting anxiety. Depression is one of Masterson's six horsemen, but he does not consider anxiety. The phenomenology of the experience suggests that it is.

The depression has its own course. In terms of the perspective of this paper, the anxiety and depression are both experienced and perhaps disavowed throughout latency and then adolescence. As adolescence morphs into young adulthood, even in the presence of therapeutic interventions, inappropriate coping responses arise for both the anxiety and depression. Interestingly there is no diagnosis that addresses coincidental anxiety and depression. The only one that remotely speaks to that coincidence is Anxiety Disorder NOS (not otherwise specified). A mixed diagnosis is in the works for the next version of the diagnostic manual that can incorporate the simultaneous experience of both anxiety and depression one hopes. In DSM-IV-TR (2000), a proposed combination disorder is described thusly:

The essential feature is a persistent or recurrent dysphoric mood lasting at least 1 month. The dysphoric mood is accompanied by additional symptoms that also must persist for at least 1 month and include at least four of the following: concentration or memory difficulties, sleep disturbance, fatigue or low energy, irritability, worry, being easily moved to tears, hyper vigilance, anticipating the worst, hopelessness or pessimism about the future, and low self-esteem or feelings of worthlessness (p. 780).

The authors go on to say:

Current prevalence rates range from $1.3 \%$ to $2 \%$ in primary care settings. In community samples the current prevalence rate has been estimated to $0.8 \%$. Mixed anxiety-depressive disorder has also been found to 
be quite common in the few mental health settings in which it has been studied (p. 780).

The proposal drew a great deal of attention in and around the publication of DSM V. Yet none of the differential diagnoses include either posttraumatic stress or a personality disorder of any sort, in the context of either DSM IV or DSM V. As a result, the proposed reconsideration of the borderline personality disorder, in this argument, has no real precedent for future diagnostic changes or, for that matter, current diagnoses. Nevertheless, serially at first and then concurrently, anxiety and depression form the two pillars of the symptoms of borderline syndrome. Even Masterson's early description leans in the direction of multiple contributing factors, though he leaves aside anxiety as one of the "horsemen".

The coping responses that arise for people diagnosed with Borderline Personality Disorder are focused on relieving both anxiety and depression. Sometimes these involve drug or alcohol use and often involve unstable relationships; sometimes multiple short-term sexual liaisons; sometimes abuse-either of substances or relationships. More often than not the coping responses are inappropriate. These often are ineffectual in respect to the target symptoms of anxious reactivity and despairing depression. That is to say, they don't work.

Finally, if the individual makes his/her way into a long-term therapeutic relationship as opposed, perhaps, to short-term therapies for the individual's life events or mistakes of judgment, help can be obtained. It's the relationship that will provide the example of appropriate interactions presumably. Maybe out of desperate dissatisfaction with the previous therapists or programs, the individual meets with someone who makes contractual demands on them for long-term work (e.g. Linehan, 1993). And, he/she may comply because their personal life is at stake. It is at this point, where an individual, say in their twenties, becomes aware of their discomfiture, anxiety, and depression. They may be experiencing continuing flashbacks or troublesome memories, but, more importantly, the individual decides to try to reduce that discomfiture.

To reiterate, it appears that a series of developmental stages eventuate into what is commonly diagnosed BLPD. In my observations, often the course begins with PTSD, resulting from either physical or sexual abuse the effects of which persist with unrelenting anxiety that becomes intolerable and exhausting. The exhaustion presents as emotional, psychological, and physical eventually morphing into depression and despair. Relentless flashbacks, nightmares, and memories produce chronic anxiety. Ensuing depression and despair, and finally unstable relations or alcohol and drug abuse erupt into angry reactions or desperate suicidal attempts often accompanying failed vocational attempts or marriages. In this paper, this developmental and ontological process is examined by utilizing a case example and reference to previous research some of which contributes to the reification of BLPD.

The intention here is to tease apart the contributing features of an individual's experience that eventually become etiological "facts" in establishing a diagnosis of Borderline Personality Disorder (BLPD). Theory is paramount here. It is the theoretical position from which a disorder is viewed that influences the description of the actions and motivations that are ascribed to the individual who is observed. Primarily a diagnosis is often shorthand for a broader clinical or contextual picture of the life and actions of an individual. While sometimes useful, diagnoses are more and more utilized in justifying insurance payments or other treatment assignments. Theory therefore directs both treatment and interpretation of a problem as a result of the influence of an insurance examiner.

Meaning of the clinical and treatment language is fundamental as a result of the various influences (e.g. Barclay, 1997a; and Barclay \& Kee, 2001). However, meaning is not an easy phenomenon to understand. Interpretation produces it, but it is variable from one speaker to the next, or one writer to the next. The meaning of personality disorders often appears as factual when it continually remains both theoretical and metaphoric. That can be a problem. No real solution presents itself, only more interpretation. Thus, this essay theorizes that BLPD is susceptible to reinterpretation and that it might be that the disorder itself has lost any metaphoric power it once had and has, instead, become reified. BLPD demands deconstruction.

Reification is a complex problem in and of itself. And, previous discussions by this writer and others only dent the surface of such reification and do so barely. Nevertheless, meaning formation and theorizing affect individuals who fall under the sway of reified diagnoses. Compassion is another subtext to this essay. If BLPD can be deconstructed theoretically, it can be deconstructed clinically. As a result, in my opinion, BLPD appears as a cumulative process in the life of an individual, the stages of which each needs a compassionate response of an understanding, treating clinician.

A suggestion forming a primary subtext here is a challenge to the clinical use and adequacy of the BLPD di- 
agnosis. To begin, we can observe those features that are generally understood to establish the diagnosis. Following that we will briefly consider the stigma associated with certain diagnoses (e.g. Erikson and Kress, 2005) in an effort to critique the potential of the diagnostic manual for mischaracterization of individuals. Finally, by examining the evolution of those features in an individual's experience that eventuate into the presentation of BLPD, we might be able to understand a complex of symptoms which in fact should be treated separately.

Rather than setting out to dispute previously outlined treatment methods (Masterson, 1976; Masterson, 1981; Linehan, 1993, among others) which take the diagnosis as definitive (if not reified), this essay intends to simply question the coalescence of the complex of experiences into a personality disorder rather than understanding the phenomenology of what seem to be the separate aspects of it. It will, however, be useful to consider at the outset the foundation of, for example, Masterson's description. His theory takes a decidedly psychoanalytic perspective. I hope it can be useful to contrast that perspective with a phenomenological one.

But first: From a neurological point of view, prolonged stress can damage the hippocampus and thus impair the cortisol control mechanisms in the brain (See Sapolsky, 2004). With this function impaired, the advent of anxiety and depression are far more likely to occur than in individuals who never experienced either a posttraumatic stress reaction or continued abuse of some kind. Sapolsky's humorous explanation that "zebras don't get ulcers" points out that human beings can give themselves ulcers via their imagination, paranoia, or remembered experiences. A person can simply imagine that people are out to get them-whatever the initial cause. Perhaps, especially, abused children or teens might imagine such a thing easily. It makes sense then to presume that sexual abuse perpetrated on a child or adolescent can open the door to both anxiety disorders and depressive disorders. Some neuronal responses, which normally stop cortisol dumps due to the influence of the neo-cortex, can be damaged more or less permanently. This damage can produce intractable long-term anxiety and depression.

A sequence of responses to either chronic domestic violence, incipient child abuse or prolonged fears of repetition of a singular event such as rape seems to be typical in or at least explanatory of the personality disorder which labels people as "borderlines". The consequences of PTSD from domestic violence exposure are likely to figure prominently in the typical etiology of personality disorders and borderline personality in particular. If the sequence is examined in clinical cases, as this writer has had the opportunity to do, it may be that behaviors and speech patterns attributed to borderline personalities can be viewed as less intractable from a broadened perspective. That intractability is exactly what is in question here.

Many of the cases that this writer has observed proceeded historically from early sexual abuse resulting in chronic traumatic responses of intense fear and emotional adjustment. Anxiety responses typically arose. These include classic symptoms such as nightmares, avoidance of places that were reminiscent of the abuse, re-experiencing the abuse via traumatic memories, as well as other typical behavioral responses. The period of anxieties (and/pr panic attacks) continued through adolescence. Towards the onset of adulthood, in their early twenties, the people whom I observed became physically and emotionally exhausted by the intense unremitting anxiety.

Following this, the exhaustion appears to have developed into a depression. Self-denigration, continuation of adolescent "cutting" behaviors, low self worth, guilt, among others seemed to characterize the depressive experiences. As the anxiety and depression continued in tandem and were either the subject of psychotherapy or psychopharmacological interventions, these experiences seem only to diminish to a relative extent. Other behaviors arose which appeared to involve self-medication and avoidance of social interactions. In this context, drug and alcohol abuse as well as instability in relationships seem to come to the fore.

Masterson's earlier work (1976) presents a developmental model wherein a child's problematic attachment to mother eventually result in BLPD. As we've noted above he sees the months, 18 to 36, as fundamental for the infant in the development of BLPD. Here we can see the bases for future emotional issues, problems, and potential mental health illness. Conflicts like those described by Masterson, given a problematic withdrawal by the mother, eventuate in the developing individual in myriad ways. Clearly, certain developmental needs, when not met, provide for an emphasis of one or more of the "feelings" that Masterson rightly notes.

In his updated theory, Masterson (1981) suggests, following Mahler et al. (1975), that the rapprochement stage of development may be the appropriate time of life for the attachment difficulties to arise and eventuate into BLPD. He notes:

My earlier publications did not adequately emphasize that the normal developmental vicissitudes of the rapprochement subphase, the surge of individuation accompanying the acquisition of locomotion and speech, as well as the increased awareness of the separateness from the mother which triggers the child's 
increased sensitivity and need for the mother, become unique vulnerabilities for the borderline child. His/her very surge of individuation, which brings with it a greater need for the mother's support, actually induces withdrawal of that support, i.e. the vital process in which he/she is engaged produces the withdrawal that arrests that process and results in abandonment depression (p. 133).

\section{The Necessity of Deconstruction of BLPD Syndrome}

While the basis of psychoanalytic theory provides identifiable constructs upon which one might base a description of borderline traits, it might be equally useful to consider events of an individual's life, such as sexual abuse or rape, as a moment in development from which the traits might be seen in a different light. From this perspective, then, the social construction of such traits (e.g. Gergen, 1985) might be seen to develop from the first occurrence of an act of this kind perpetrated on the individual and the coping responses necessary to deal with it might be seen to have a developmental path of a slightly different sort. If we examine, the so-called "borderline traits" from the developmental point of view as separate entities in and of themselves, then perhaps what appears is the necessity of treating those traits as unfolding as separate and identifiable as well as treatable problems. Masterson's Six Horsemen of the Apocalypse, while arising from maternal withdrawal, can be seen separately. And, maternal withdrawal - neglect, as it were - is a common but not exclusive trauma at the root of the series of emotional reactions that follow.

An interesting semiotic problem of DSM IV TR (American Psychiatric Association, 2000) was that for personality disorders, "features" is used in one instance and "traits" in another. From the point of view of effective description, the difference might be meaningful in terms of the less specific meaning of "features" and the more ingrained character flaws of "traits". In the former, implications might be seen to draw out both responses to experience and expressions of the results of those responses. In other words, the presenting expressions and phenomena of the complex of behaviors and tendencies-features are potentially misunderstood as permanent and unremitting "traits" of an individual's character. The latter stands in contrast to a phenomenological description of both subjective (and deeply personal) responses to say trauma and the behaviors or problems that arise in its wake as consequence. I will choose to use "features" in order to emphasize the phenomena in contrast to fully formed, unremitting, fixed, established, if not inherent and reified "traits" of personality. As so called Axis II diagnoses, personality disorders are quite often conceived of as life long, often resistant to treatment, and difficult at best. The presence of "traits" develops from what are temporary "states" in the etiology of personality disorders.

An implication of the argument presented here is that personality is not necessarily fixed but rather an evolving aspect of an individual's experience. While not an earthshaking implication, it may contribute to a more hopeful attitude that practitioners might work from. This revised attitude might instill hope where there is none in psychotherapists who may consult with individuals who would be diagnosed with BLPD.

In contrast to DSM descriptions, I would like to offer a description of problems that a woman traumatized by childhood sexual and physical abuse experienced. In my clinical practice, particular women wind up displaying what would very likely be diagnosed as "traits" of BLPD. When a particular woman was a child or adolescent, trauma of child sexual abuse occurred. She first experiences anxiety that is typical of Posttraumatic stress. This anxiety often arises with accompanying behaviors such as scanning, hyper vigilance, self-recrimination ("it was my fault, I caused it”), intermittent panic episodes, dissociation, flashbacks, nightmares, sleep difficulties and feelings of low self worth among others. Van der Kolk, McFarlane, and Weisaeth (2007) edited a text that contains germane chapters. Van der Kolk, in a chapter entitled, "The Body Keeps the Score: Approaches to the psychobiology of Posttraumatic Stress Disorder”, develops a description which considers, among others, Damasio's theory of the inextricability of emotion and cognition. Van der Kolk thinks that "the body keeps the score"-in other words, the body receives a "reality" imprint from trauma that is memorized, as it were, in the nervous system (see also Damasio, 2005 and Sapolsky, 2004 among others). He writes:

Stress-induced serotonin dysfunction may lead to impaired functioning of the behavioral inhibition system; this may be related to various behavioral problems seen in PTSD, including impulsivity, aggressive outbursts, compulsive reenactments of trauma related behavior patterns, and a seeming inability to learn from past mistakes (p. 225). 
Van der Kolk also suggests that trauma has psychophysiological effects. He says, "Reactions in PTSD occur on two very different levels: 1) In response to specific reminders of the trauma, and 2) in response to intense neutral stimuli (e.g., loud noises), signifying a loss of stimulus discrimination” (p. 219). Clearly, cognitive functions can be impaired even in those who have strived to overcome the emotional impact of the trauma. It's a natural response which in some ways acts defensively both for the body and soul.

After a number of years (or months in the case of an older teen) the tedium of the anxiety and the accompanying problems and experiences takes its toll. An emotional and consequently physical exhaustion ensues. It continues, manifest in deeper feelings of low self-esteem, sadness, regret, confusions ("why did this happen to me", why would my dad do such a thing), acting out (in some cases) which may involve threats of suicide, property damage and a variety of self-destructive behaviors. At this point, hospitalization (or at least assessment for psychiatric medications) may occur if some relatives are being appropriately responsive. At such a time a variety of behavior patterns may be, if you will, contagious to the child or teen. In other words, a teen that is hospitalized in a psychiatric facility may be discharged with habits learned during treatment from other patients there. Claiming to hear voices might be one such behavior (in the absence of schizophrenia). Another might be "cutting"-a rapidly growing common practice of teens. It may be that these behaviors are not derived from either original psychotic symptoms or from prior and long standing self-destructive behavior. Regardless of diagnoses applied to the teen, the anxiety continues with such intensity that it produces an exhausting depression. At this point there are two problems that confront both the individual and a treating practitioner. When the teen, struggling with these combined issues, becomes a young adult when alcohol is obtainable, or as a teen using substances and alcohol, self-medication with various substances is often used to try to combat the now growing complex of issues including both anxiety and depression.

During the time of substance use, self-destructive behaviors and continued flashbacks and dreams due to the trauma, the young woman will likely become increasingly untrusting of men. As a result, relationships are likely to suffer. During young adulthood, multiple relationships, serial monogamies interrupted by intermittent affairs, unstable and superficial relationships are likely. Trust becomes a major issue. Loneliness can rejuvenate venerable behaviors of self-destructive thoughts and actions, intermittent seemingly psychotic imaginations as well as cutting or other types of self-mutilation. In certain cases, in my clinical experience, serious weight gain can develop as a sort of body armor. There is no identifiable time-line for the evolution of this coalescence of presenting subjective experience and actions, but young adulthood seems the time that serious treatment may be sought. When it is sought a diagnosis of BLPD is often applied to the patient. As a result, sometimes it is difficult to find a practitioner who deals with presumably intractable personality disorders.

\section{BLPD in Treatment}

It may be that our hypothetical individual is met with rejection from treatment or in a phone call that requests treatment, because many practitioners often feel self protective and say about such an individual, "I don't treat Borderlines" often in a dismissive manner - though to the potential patient, say "my practice is full". Or, a martyr practitioner might say in describing their practice, "I treat Borderlines because they represent a challengeof rigid characters, subject to unremitting psychopathological illnesses”. Given a likely universal commitment to care, many reactions to the so-called personality disorder can occur simultaneously in practitioners who do actually want to help-including the two extremes noted. Sometimes a potential patient will announce that they have been so diagnosed.

Regardless, if the coalescence of subjective experience and actions or habits is given the diagnosis of BLPD, many of the continuing trauma-stimulated anxiety issues (including dissociation, panic, flashbacks, emotional instability, lack of trust) can take a back seat to the so-called character disorder. The low self worth issues that might have eventuated into frank depression (including self-mutilation, suicidal thoughts and threats, sadness and low self esteem) can also be relegated to ancillary status. The trauma becomes (if noted at all) a secondary feature of the presenting problems. The depression can be connected to the instability of personality and not a problematic presenting feature in and of itself. In fact, personality can be understood as a problem of neurotransmitters, in that character is believed to be biochemical at base. Again the trauma takes a back seat, as do ensuing symptoms and depression.

As I saw in training videos presented by Masterson, an individual, traumatized at a young age and who in 
seeking stability ended up having had numerous broken marriages, abuses and rejections, presenting with typical symptoms of BLPD, was depicted as an example of that diagnosis. The cultural and economic roots of the woman's lived instability were not presented as part of the description. Her low economic status was not considered. So social construction of attitude is relevant here. She also presented with somewhat low intelligence, which seemed to complicate the complex of other symptoms including reactions to the abuses of ex-husbands that were not brought into the diagnostic description. Instead, she was simply an example of BLPD, and all of her symptoms (which were focal points) simply supported the diagnosis.

In another case Masterson presented, an obvious lesbian who was also abused as a child/teen and wore masculine clothing was critiqued for that very choice. And, typically, instability, drug use, and multiple relations were emphasized as important presenting problems. The obvious sadness due to cultural prejudice towards sexual orientation and social criticism were not brought into the description. The symptoms were typified as consistent with BLPD.

To reiterate, the various symptoms contributing to a diagnosis of BLPD should be considered separately. Each demands its own focus. Each functions, if not independently, at least separately from one another in view of the lived experience of the individual. Interestingly, the DSM IV/TR took pains to distinguish between "categorical and dimensional"' ways of describing individuals (pp. 3-11). Diagnosis, as it is proffered in that manual, is clearly categorical, and limited. Unfortunately, this publication has a hegemony that is often overwhelming in the field. And personality disorders, as it were, have the unspoken underlying power of this hegemony. From a more multi-dimensional point of view, the eventuating or developing aspect of the experience and "being" of the individual is perhaps obscured by this categorical sort of description. Masterson, a highly respected practitioner, treating people afflicted with BLPD, suggests a reality-based and literal approach to both understanding and treating this disorder. In some respects, his influence (in spite of its psychoanalytic acumen), coupled with the hegemony of DSM, has an obscuring effect. The argument here is that what gets obscured may very well be phenomena and experiences of an individual that go untreated, de-emphasized, or in the worst cases ignored to the detriment of the individual in treatment.

\section{The Case of Dana}

Take for example, the following case. Dana, as I will call her (not her given name), was a client in my office who returned to treatment intermittently after various breaks. Originally, she came for treatment because she was in the throes of leaving her abusive spouse. I saw her for a number of months. Then she broke off treatment. Dana returned to treatment some years later as a middle aged woman who described herself as depressed, very anxious, and suffering from panic attacks. The original referral source had said that she was "a borderline" and was hoping that I was someone that could "put up with her mouth". By this he meant that he thought that profanity and obscenity would not put me off. He intimated that she had been molested and abused and she was a particularly "tough" woman. Her presentation was as expected given the brief introduction that the referral source had provided. But, what struck me immediately was her tough veneer only thinly covering a fragile and sad person who was in touch with the realities of her world-especially as these related to the way men pursued her and treated her poorly. She was married, but had consistently degrading things to say about her husband. She was having an affair with a man who satisfied her sexually but was not her idea of a long-term partner.

She had tried to make the abuse public at some point in her teens by telling her mother. Her mother told her at the time that she was "a liar". This caused Dana a great deal more confusion. She decided to bury her memories and not approach anyone else because she feared she would be disbelieved and discredited again by her mother. She became a classic "acting out" teen. Her anxiety however did not abate. She continued to have flashbacks and nightmares.

She reported a history of both physical and sexual abuse as a child, and rape in the context of her marriage in an atmosphere of threats and violence. She would be dragged by the hair, punched, and sexually assaulted both vaginally and anally. She had been working a job successfully, parenting her young child, and had engaged a lawyer to help with the legal aspects of leaving her husband. She came from a south bay county and moved to a North Bay county in Northern California, in the San Francisco Bay Area, where she was in the process of "restarting her life" as she said. She was clearly afraid of her estranged spouse showing up and kidnapping her child or herself. She was more than cautious. But she was not necessarily paranoid being that the man represented a very real threat. She came to the office with two adult friends who were quite protective because 
they knew the potential violence that her spouse was capable of.

At first, she focused on her story - especially the abuse as a child and then her abusive spouse's manipulative control issues. Soon she began describing her flashbacks and nightmares which continued to plague her. They always included the abusive spouse, and sometimes her dreams included her violent retribution and various forms of murder including bludgeoning and knifing the man. She also described her recent, at that time, relationships with women which inevitably were unstable and fraught with arguments. Often these relationships were short lived.

Additionally, Dana's physical health had begun to deteriorate. She was diagnosed with a spine problem that was operated on, as well as a tentative diagnosis of MS. It seemed tentative because three neurologists were involved in attempting to confirm a finding made by an MD in San Francisco. One confirmation seemed conclusive only to be countermanded by another more recent one that suggested that any observed lesions were not necessarily objective proof of MS since patients in general could present with similar lesions attributable to a lesser diagnosis.

In the meantime, a prescription of a variety of interferon became both tedious and long lasting. Finally, the infusion of interferon seemed to be debilitating in and of itself. This writer was prompted to inquire by mail of the MD who had originally made the diagnosis, explaining that the patient was confused as to the reality of the condition and experienced stress as a result of the interferon treatment.

Many of our meetings were fraught with discussions of what the outcome of the MS would be. Would it be a paralysis that would confine Dana to a wheelchair? Would it be something that could be controlled by medications and perhaps its progress stalled? Might there be concomitant illness that would accompany the deterioration? Were symptoms that Dana was experiencing related to MS or were they separate issues? One ancillary practitioner also phoned me to inquire if I thought Dana was suffering hypochondrias. I considered the possibility, but rejected it since the diagnosing MD sent me a letter confirming PTSD as well as MS. In fact, the anxiety that she suffered from the chronic posttraumatic stress continued to be exacerbated by a variety of life events, not the least of which was the inconclusive threat of MS.

Over the years that Dana came for treatment, this anxiety persisted. It manifested in a number of ways. Primarily, it prompted angry outbursts that seemed self protective rather than aggressive. Of course, this was an opinion not always shared by the targets of the anger. As time went by, the anxiety and self-protective behaviors grew tedious for her subjectively. No explanations would suffice in breaking through the subjective "reality" of the anxiety and coping responses. In other words, cognitive behavioral interventions were up against a very solid coping mechanism that at least at first seemed impenetrable. What began to happen was that Dana would come to the office quite down trodden. Her attitude was characteristically depressed. The anger that had at first been directed outwardly was now in great proportion (though not completely) directed at her. Her relationships were tenuous to begin with and seemed to her doomed from the start. That many relationships were short-lived was evidence, for her, that seemed to confirm her experience of low self worth. She began to believe her own story of gloom and doom.

It appeared that her depression was growing out of a sense of exhaustion and frustration both attributable to long term anxiety. It seemed as if the depressive problems were directly related to the tediousness of the anxiety and its tenacious, ineffective coping mechanisms. Of course, self worth was an issue since childhood due to the confusions perpetuated by poor parenting, non-protective mothering as well as abject physical and sexual abuse. Nevertheless, it seemed to grow in response to the continued anxiety that manifested as a hyper-vigilance and occasional paranoia. Anxiety would increase for a number of months, and soon following that the depressive symptoms followed. By the time she was referred to me, she had been characterized by her diagnosis of BLPD.

In more recent relationships, Dana continued to exhibit the suspiciousness and anxiety that was characteristic of her typical attitudes. She would blame herself for intense arguments when she was not the culprit. Her choice of partners was limited by her social world. Her interests outside of those circles were somewhat limited. A relatively long-term relationship ended in acrimony on both sides, but because of economic necessity it continued functionally with no romance or sexuality involved. Dana's sexual issues were difficult for her to express and bring out in therapy. It took her quite a long time to express them. As they emerged in our conversations, Dana seemed to find some solace in self-understanding. She also began to say things to her friends such as: she needed to "get to know Dana"; saying also in treatment, "I need to understand myself" before she would get into relationships again. Interestingly, she began to explore different sexual relationships that were not necessarily tied to a plan for permanence. She began to become aware of her potentially volatile anger issues and began to 
curtail some of the negativity. After finally leaving her abusive husband, as noted above, she sought therapy. She dropped out within the year although her immediate concern was her angry lashing out towards friends and her child.

After a hiatus of a number of years, Dana returned to therapy. One of the major changes that had finally taken place in Dana's life was that she became, for all intents and purposes, a lesbian. She took on a female lover, who interestingly enough, also was quite angry and attempted to abuse Dana. However, Dana utilized her own anger to display that affect in both defensive and threatening ways. In developing an empathic therapeutic relationship with Dana, it became obvious, that she believed her actions fully justifiable. A sort of sexual exploration characterized her subsequent relationships although they were few and far between.

Furthermore, one of her partners persuaded her to explore the use of drugs and in some cases hallucinogenic substances to supposedly enhance the sex. Interestingly, this particular partner turned out to be conniving and manipulative as well as peculiar in her sexual interests. To the extent that the peculiarities began to feel abusive, Dana spoke about them in therapy and decided to break it off. She has, however, brought that series of experiences into her catalog of low self worth memories. It had become a topic of therapeutic exploration especially after a hiatus in her treatment. When she had returned to therapy, she was especially interested in what was noted above as her exploring "herself." This aforementioned relationship figured into her traumatic history also.

Dana began her therapy because of her "anger" problems. This was her oft stated and most important issue. Some of the reasons that she would grow angry included, for example, her mother's non-protective attitude towards her as a teen. Dana remembers experiencing her mother engaged in sexual activities quite without a sense of either awareness of appropriate boundaries as well as an unfettered attitude towards bringing multiple partners into the home. While some of the lovers didn't engage with Dana, when her mother chose an abusive husband, Dana felt that she needed to protect her mother from the abusive and aggressive behaviors. So, she was exposed both to overt sexual behavior and also domestic violence that often accompanied it. A lack of discretion and privacy on mother's part created what might be called the "soft molest" in that though Dana was not necessarily touched or molested at that point in time, she was exposed at a young age to adult sexuality (as well as drug and alcohol abuse). This exposure seemed wrong to Dana when she reflected on her memories of the experience. In any case, she attributes what she calls "wrongness" in retrospect to those events. She also wound up thinking that there was a relationship between aggression and sex.

Aggression was linked to sexuality in her teens when she met the father of her child. When Dana was essentially abducted by a man a few years her senior, this emotional abduction was made possible, it appeared by the threat of violence if she did not pay attention to the man. At the outset of the relationship, she remembers that he was much more sympathetic and "sweet" than he wound up being once she was securely under his sway. Often, once disempowered in the relationship, Dana's former husband would rape her and sodomize her in spite of her protests.

She finally divorced the man. She soon began to consort with other women. Her relationships subsequently would at first be based on her irrational beliefs that her anger and acting out was justified by the aggression and anger shown by her partner. She broke windows and threw phones among many other defensive/aggressive behaviors. In order to support her in taking a closer look at her own reactivity, some of her underlying assumptions needed to be gently confronted.

Helping her to understand herself was a product of this type of approach in keeping with her intent. But, it became clear, that her abusive experiences needed to be expressed and outlined to a certain extent. Stories about an erstwhile "step-dad" often walked around the house naked, as well as being threatening if not violent towards her in the interest of parenting her and disciplining her "wild" behaviors in elementary school and junior high.

Being present to her experience of both familial threats and exposure to sexuality at a young age as well as her experience of her coercive husband seemed to be the most supportive and empathic approach.

At the center of her experience was the memory of abuses. The treatment of her abusive experiences-molest, domestic violence and rape-was the first order of business, it seemed. This is where her core beliefs began to take shape.

Dana's anger did not arise from the situations in which she found herself. Rather, it arose from the way in which she experienced the situations in respect to her own conception of what was central to those experiences. This conception was constituted in a netherworld between the teen, Dana, and the world that seemed at that time both threatening and confusing. Out of that conception, the young adult Dana utilized her habitual means of self- 
defense. Namely she used aggression to thwart the possibility of either abuse or-more central, violence that has been associated with the anger of others. She wound up, as a result, in domestic abuse in many relationshipsboth sexual though sometimes initially friendly.

The childhood abuse began a habitual response that was primarily designed to protect her. Dana brought herself to therapy because the "anger" wasn't working that well for her. The anecdotes of episodes in which anger showed up were her immediate presenting stories. Only after many months did she bring out her experiences as a child or as an abused teen wife.

Dana was often fearful that her ex-husband would be stalking her. Her fears were multiple and eventuated into high anxiety. Anxiety arises classically in response to posttraumatic stress disorder. It seems, the stress of molest or abuse experiences results in protracted anxiety arising during a formative stage of the young Dana's development.

Masterson (1976) examines with great scrutiny the developmental experience that occurs just prior to adolescence-from 10 to 12. At this point in development, he suggests, the individual experiences a sort of second separation/individuation stage during which a variety of stressors create a need for the ego to produce defenses against a sense of loss that originally typifies the infant's first separation. This infantile separation is a developmental moment, in object relations theory, around which the ego begins to take shape. If there is a dependable mother figure, the ego begins to differentiate itself. During the developmental stage between 10 and 12, a similar differentiation and separation from the mother needs to take place. In the healthy child, no "splitting" occurs, whereas an impaired bonding with the mother causes the child's needs for coping responses to become overweening. As a result, Masterson suggests, "acting out" occurs among other coping behaviors. This serves to support the notion that in Dana's history, the abuse created a sense of instability in the maternal/child relation and produced what Masterson noted as the onset of the "six horsemen."

In Dana's case, which this article suggests is typical, the consistent instability in the parental relationships produces serious anxiety. Masterson (1976) notes that in the younger child, clinging to the mother occurs and the child can develop a school phobia. This is a prototypical situation in which separation anxiety can arise as a reappearance of infant separation and its anxiety experiences. Dana remembers feeling very rebellious against her mother and step dad as well as remembering "cutting school" and eventually refusing to go to middle school and often hiding that from her inattentive parents. She finally quit school and married the abusive man who eventually fathered her child.

So, for the individual that Masterson describes, and for Dana, the phobias and anxieties result in exaggerated rebellion. It is quite different from an individual who will develop into an antisocial child. Instead, a borderline personality is foreshadowed in a pre-borderline adolescent. This style of personality, according to Masterson's classic description, is founded upon anxiety that reacts to separation from mother, and the need to break off any "clinging" and school phobia. Masterson (1976) also suggests that in this prepubescent stage (10 to 12) "a second marked developmental maturation of the ego occurs, creating a period of special vulnerability." (p. 48) But most importantly it is a contributing and defining factor of BLPD.

Dana upon beginning therapy, told her tales of defending herself against predatory-even her lovers. Her primary defense against her experience of anxiety that began to mature into her adolescence was anger. But the rebellions and the angry affect didn't diminish the anxiety. As a result, she ran off with (and/or was dragged off by) her husband in an attempt to substitute that relationship for an appropriate maternal relation. Unfortunately, substitutions of this sort never provide the fulfillment that actual appropriate parenting or care can provide.

As a result, a treating clinician must bear witness to that reality-one that Masterson clearly points out. But this essay theorizes the problem somewhat differently. Compassion demands that the evolution of the problems that the so-called "borderline" faces are approached in a similar manner to the way they evolve. That is, it begins by addressing the anxiety, either resulting from PTSD as I have seen it, or resulting from painful separation from the mother due to maternal insufficiency or both. It proceeds into a depression as a result of the unrelenting anxiety. Sometimes irrational thinking (perhaps momentary psychotic transient experience) arises. Often, substance abuse or multiple sexual relationships are chosen as unhelpful coping mechanisms. These multiple presenting symptoms have congealed into a personality pattern that seems to have become reified. That is the concept that has been reduced to "borderline personality" is a real thing for practitioners. The suggestion of this essay is that practitioners view the phenomena of the syndrome as separate entities and from a phenomenological 
perspective (e.g. Merleau-Ponty, 1962, 1963).

\section{Conclusions}

In conclusion, it appears that "borderline personality disorder" can be seen as a series of problems and issues and contexts, all of which are intertwined inextricably. At first, trauma produces physiological effects which become embedded in the memory, and "somatic markers" (e.g. Damasio, 2003, 2005) which mark the emotional reaction to the trauma and produce the effects described above by Masterson. In particular, the reaction which imbues incidental and mundane events with both an exaggerated startle response as well as emotional affective meaning which is more than troublesome and is often psychologically and experientially disruptive. These markers set in motion an anxiety (and often hyper-vigilance) which is accompanied by various attributes of stress such as flashbacks, nightmares, social anxieties that are sometimes debilitating, anger responses that can be embarrassing and disruptive to relationships, coping mechanisms which include drug and alcohol use and abuse and difficult sexual responses and/or impotence and frigidity.

So it seems the first order of clinical business is to process and work with such phenomena in a compassionate and mindful way, directing the individual, at times, to self-observation which might reduce those reactions and establish some pre-frontal cortical inhibition. In the case of Dana, this process was enduring and continues to be. While a cure is not necessarily in sight, reduction of symptomatic reactions has been somewhat effective as well as providing a modicum of self-observation. The trauma must be considered at first as the focus of a sort of crisis intervention. Following that, the ongoing anxiety can be addressed in what is likely to be long-term psychotherapy as well perhaps with psychopharmacology.

Next, the anxiety-produced exhaustive depression needs to be approached. Again compassion is the key. Psychiatry can also provide medication support that reduces the feelings of ominous and never-ending sadness, but leaves open the possibility of self-observation, the focus of which can be on the derivation and etiology of the sadness with reminder that it is not, however, much it may feel, permanent. Finally, the attributes of the coping responses need to be singly addressed. In some cases, utilizing ancillary alcohol or drug treatment providers is warranted.

In my opinion, it seems that treating the evolution of the traumatic responses as serial problems developed over the course of a lifetime is a focused and theoretically (i.e. deconstructed) compassionate approach. This approach does not agglomerate the separate and equally disconcerting multiple problems into a diagnosis of a real, if not reified, "personality disorder". Instead, mindful of the timeline of the traumas and issues of dysphoria and instability, it approaches each attribute of the "marked" physiological, emotional and psychological challenges that the individual faces. Merleau-Ponty (e.g. 1962, 1963, 1971) reminds us that it is the "embodied subject" who suffers. And that perception, say of a diagnosis, is interpenetrated by context, time, perspective and attitude. "Borderline Personality Disorder" may appear at first to be a coherent, identifiable character problem, but that language-bite may turn out to be a facile way of labeling the complex experience of an individual whose life has been shaped by the peculiar and often criminal behaviors of others. Clearly, a helpless child or pre-teen or teen does not invite the character shaping behavior of others. Social construction of a series of reactions, anxiety, depression, panic, instability and fearfulness is not an internally generated experience. Rather the anxiety, depression and confusions are the consequence of exposures to manipulative, abusive and self-serving others. The resultant series of symptoms must be seen as similar. Thus, rather than an intractable Axis II character disorder, the series needs separate attention to each of the Axis I disorders as they unfold in the story of the person in treatment. Compassion demands that the separate aspects of that experience be approached with caution and understanding based not on one interpretation in one theoretical realm (such as psychoanalytic theory) or one treatment regimen, but rather a broad realization encompassing all the levels and complexities of the problems of the individual diagnosed with BLPD. Theory is paramount here. It is the theoretical position from which a disorder is viewed that influences the description of the actions and motivations that are ascribed to the individual who is observed. This is not only the case here, but also an on-going problem in the language of psychiatry and psychology (e.g. Barclay \& Kee, 2001). It is a semiotic problem. What this article attempts to outline is that when semiosis produces a diagnostic description that has become reified, practitioners can be misguided in their approach to its emotional and psychological issues. Seeing, in this essay, how it is possible to deconstruct the diagnosis of the borderline syndrome, a practitioner might be inspired to treat the multiple symptoms as separate entities. Thus, the development of the syndrome (from molest/sexual/physical abuse, to anxiety/panic, posttrau- 
matic stress, depression, drug/alcohol abuse, unstable relationships and multiple sex partners) can provide a blueprint for the development of the treatment if the practitioner follows that lead.

\section{References}

American Psychiatric Association (2000). Diagnostic and Statistical Manual of Mental Disorders DSM-IV-TR (Text Revision, 4th ed.). American Psychiatric Publications.

Barclay, M. W. (1997a). The Metaphoric Foundation of Literal Language: Towards a Theory of the Reification and Meaning of Psychological Constructs. Theory \& Psychology, 7, 355-372. http://dx.doi.org/10.1177/0959354397073004

Barclay, M. W. (1997b). Metaphoric Truth and Narrative Structure: Implications for Understanding and Treating Patients Exhibiting Dissociative Phenomena. In S. Krippner, \& S. Powers (Eds.), Broken Images, Broken Selves: Dissociative Narratives in Clinical Practice. New York: Bruner-Mazel.

Barclay, M. W., \& Kee, M. (2001). Towards a Semiotic Psychotherapy: Semiotic Objects and Semiotic Selves. Theory \& Psychology, 11, 671-686. http://dx.doi.org/10.1177/0959354301115005

Damasio, A. (2005). Descartes’ Error: Emotion, Reason, and the Human Brain (Revised Penguin ed.). New York: Penguin.

Damasio, A. (2003). Looking for Spinoza: Joy, Sorrow, and the Feeling Brain. San Diego, CA: Harcourt.

Gergen, K. (1985). The Social Constructionist Movement in Modern Psychology. American Psychologist, 40, $266-275$. http://dx.doi.org/10.1037/0003-066X.40.3.266

Linehan, M. M. (1993). Cognitive-Behavioral Treatment of Borderline Personality Disorder. New York: Guilford Press.

Mahler, M., Pine, F., \& Bergman, A. (1975). The Psychological Birth of the Human Infant. New York: Basic Books.

Masterson, J. F. (1976). Psychotherapy of the Borderline Adult. New York: Bruner/Mazel Inc.

Masterson, J. F. (1981). The Narcissistic and Borderline Disorders. New York: Bruner/Mazel Inc.

Merleau-Ponty, M. (1962). Phenomenology of Perception. London: Routledge and Kegan Paul; New York: Humanities Press.

Merleau-Ponty, M. (1963). The Structure of Behavior. Boston: Beacon Press.

Merleau-Ponty, M. (1971). The Primacy of Perception. Evanston, IL: Northwestern University Press.

Sapolsky, R. (2004). Why Zebras Don't Get Ulcers (3rd ed.). New York: Holt/Owl.

Van der Kolk, B., McFarlane, A. C., \& Weisaeth, L. (2007). Traumatic Stress: The Effects of Overwhelming Experience on Mind, Body and Society. New York and London: Guilford Press. 